\title{
Remission of asthma in the middle aged and elderly: report from the Obstructive Lung Disease in Northern Sweden study
}

\author{
Eva Rönmark, Elsy Jönsson, Bo Lundbäck
}

\begin{abstract}
Background-Remission of asthma in adults has been considered to be low but is still not well documented. In children remission occurs with a rate estimated at approximately $\mathbf{5 0 \%}$. Remission of asthma in middle aged and elderly subjects was investigated as part of a population based study of respiratory diseases in Northern Sweden.

Methods-In $198686 \%$ of 6610 subjects participated in a questionnaire survey. After a clinical validation study 300 subjects were diagnosed as having current asthma. In 19965935 subjects of the cohort could be traced for a third survey and $87 \%$ participated. Of the subjects with current asthma in 1986, 267 participated. In addition, 60 symptomatic subjects were classified as suspected asthma and 58 of them participated in 1996. Remission of asthma was defined as no recurrent wheeze, no attacks of shortness of breath, and no use of asthma medicines in 1996.

Results-Remission of asthma during the 10 year period under study was $6 \%$. In subjects with suspected asthma, remission occurred in $22 \%$. The average annual remission rate was less than $1 \%$. Remission was associated with previously mild disease and cessation of smoking.

Conclusion-Remission of asthma or the disappearance of its symptoms to an asymptomatic latent phase appeared to be rare in middle aged and elderly subjects. (Thorax 1999;54:611-613)
\end{abstract}

Keywords: asthma; remission; middle age; elderly; epidemiology

Centre

E Rönmark

Department of Lung Medicine and Allergy, University Hospital of Northern Sweden, Umeå, Sweden B Lundbäck

Correspondence to: Dr B Lundbäck, Respiratory Epidemiology Unit,

Department of Occupational Health, National Institute for Working Life, P O Box 7654, SE 907 13, Umeå, Sweden.

Received 19 October 1998 Returned to author

1 December 1998

Revised manuscript received

1 March 1999

Accepted for publication

24 March 1999

Asthma in adults is regarded as a chronic disease, although it may remit. Only a few studies of remission of asthma in adults have been published. ${ }^{12}$ Before adulthood the remission of asthma has been considered to be around $50 \% .^{3-5} \mathrm{~A}$ recent publication has confirmed that adult asthmatic subjects may outgrow their asthma, although the remission rate decreased with increasing age. ${ }^{6}$

The paucity of studies of remission of asthma means that the factors predicting remission are largely unknown. Low forced expiratory volume in one second $\left(\mathrm{FEV}_{1}\right)$ and severe disease are factors reported to have a negative effect on remission, ${ }^{16}$ while mild disease $^{1}$ or early intervention ${ }^{6}$ are associated with remission.
As part of a population study, the Obstructive Lung Disease in Northern Sweden study (OLIN), an adult cohort with asthma, has been followed for 10 years. The aim of this study was to estimate the proportion of cases of remission of asthma in middle aged and elderly subjects, and factors related to remission.

\section{Methods}

In 1986 a cross sectional survey in Northern Sweden was performed in order to estimate the prevalence of respiratory diseases. ${ }^{7}$ The study sample consisted of all subjects aged 35-36 years, 50-51 years, and 65-66 years from representative areas in the province. Of the 6610 invited subjects $86 \%$ participated in a postal questionnaire survey followed by structured interviews and lung function tests. The questionnaire was validated ${ }^{8}$ and 300 subjects $(5.3 \%)$ were classified as having current asthma. The first follow up survey of the cohort was performed in $1992^{9}$ and the second in 1996 when $87 \%$ of 5935 traced subjects participated.

STUDY POPULATION

The following criteria were used for asthma.

\section{Clinically defined asthma}

The 300 subjects who in 1986 reported a history of current asthma (at least two attacks/ periods during the last 12 months) including at least three of the following: recurrent wheeze, attacks of shortness of breath, at least two asthma provoking factors, normal breathing between asthma attacks or periods of asthma.

In all but 21 subjects a positive reversibility test (increase in $\mathrm{FEV}_{1}$ of $>15 \%$ and $>2 \mathrm{dl}$ ) or a positive methacholine test $\left(\mathrm{PC}_{20}<4 \mathrm{mg} / \mathrm{ml}\right)$ or case notes verified airway variability. The remaining 21 subjects had a convincing history of asthma. ${ }^{8}$

\section{Suspected asthma}

Sixty symptomatic subjects not fulfilling the criteria for asthma were classified as suspected asthma.

Furthermore, the following categories of asthma were based on the 1986 questionnaire study.

\section{Self-reported asthma}

The subjects who answered yes to "Have you ever had asthma?" and reported either asthma symptoms or use of asthma medicines.

\section{Physician-diagnosed asthma}

The subjects who answered yes to "Have you been diagnosed as having asthma by a 
Table 1 Participation and remission of asthma in the different asthma categories, 1986-1996

\begin{tabular}{lllll}
\hline \multirow{2}{*}{ Asthma categories } & \multicolumn{2}{l}{ Participation, $n$ (\%) } & & \multirow{2}{*}{ Remission, $n$ (\%) } \\
\cline { 2 - 3 } & 1986 & 1996 & & 1996 \\
\hline Clinically defined asthma & 300 & $267(89)$ & & $16(5.8)$ \\
Suspected asthma & 60 & $58(97)$ & & $13(22.0)$ \\
Self-reported asthma & 278 & $225(81)$ & & $17(7.6)$ \\
Physician-diagnosed asthma & 255 & $202(79)$ & & $14(6.9)$ \\
Users of asthma medicines & 283 & $231(82)$ & & $13(5.6)$ \\
Users of asthma medicines & 283 & $231(82)$ & & $30(13.0)^{\star}$ \\
\hline
\end{tabular}

${ }^{\star}$ Number (\%) of subjects who had stopped using asthma medicines, irrespective of whether or not they were free from symptoms (in remission).

physician?" and reported either asthma symptoms or use of asthma medicines.

Users of asthma medicines

The subjects who reported use of asthma medicines.

\section{STUDY DESIGN}

At the follow up study the same questionnaire was used as in the 1986 survey. ${ }^{78}$ Remission of asthma was defined as no use of asthma medicines, no recurrent wheeze, and no attacks of shortness of breath, according to the postal questionnaire in 1996. Further structured interviews were performed in the asthmatics in remission in 1996.

In order to evaluate the representativeness of the asthmatic patients still participating in 1996, demographic and clinical data from 1986 were compared with data on the nonparticipants in 1996 and with those who had died.

STATISTICAL METHODS

The $\chi^{2}$ test was used for bivariate comparisons and multiple logistic regression analysis was used to assess the simultaneous influences of possible determinants of remission including morbidity variables, age, sex, smoking habits, family history of asthma, socioeconomic group, and occupation.

\section{Results}

Of the 300 subjects diagnosed as having current asthma in 1986, one could not be traced in 1996 and 20 had died. Of the asthmatic subjects who could be traced, 267 (96\%) participated in 1996, which corresponds to $89 \%$ of the whole asthma cohort from 1986 (table 1).

The subjects with asthma who had died since 1986 had more severe disease than the other asthmatic subjects (table 2).

REMISSION RELATED TO DEMOGRAPHIC DATA AND SMOKING HABITS

In 199616 subjects (6\%) with the clinical diagnosis of asthma from 1986 were in remission. No significant differences by age and sex were found. In 1986 seven of the 16 subjects were smokers and two were exsmokers, while in 1996 five of the smokers had stopped smoking. With regard to socioeconomic group and profession, the cases in remission were distributed without any specific pattern. Neither presence nor lack of a family history of asthma was associated with remission.

Of the 58 subjects with suspected asthma, 13 $(22 \%)$ were in remission in 1996 . Six of them were smokers in 1986 and all six had stopped smoking during the 10 year period under study. Of those who fulfilled the different questionnaire based criteria for asthma, about $6 \%$ were in remission (table 1 ).

REMISSION RELATED TO MORBIDITY DATA

There was a trend for the subjects in remission in 1996 to have a lower prevalence of persistent wheeze and chronic productive cough in 1986. A significantly smaller proportion used asthma medicines compared with asthmatic subjects who had active disease in 1996 (table 2). No significant differences in the age of onset or the duration of asthma was found between the asthmatic subjects in remission and those with active disease.

\section{MULTIVARIATE RELATIONSHIPS}

The lack of daily use of asthma medicines, absence of chronic productive cough and of persistent wheeze in 1986, all indicators of mild disease, were factors showing a trend for remission 10 years later. Cessation of smoking seemed to be related to remission of asthma, although it

Table 2 Characteristics in 1986 of the asthmatic subjects who in 1996 were in remission and who not were in remission, respectively, the asthmatics who did not participate in 1996, and those who had died since 1986. Differences (p value) between remission vs non-remission, non-participants vs participants, and deceased vs all others

\begin{tabular}{|c|c|c|c|c|c|c|c|}
\hline \multirow[b]{2}{*}{ Characteristics } & \multirow[b]{2}{*}{$\begin{array}{l}\text { Remission } \\
(n=16)\end{array}$} & \multirow[b]{2}{*}{$\begin{array}{l}\text { Non-remission } \\
(n=251)\end{array}$} & \multirow[b]{2}{*}{$\begin{array}{l}\text { Non-participants } \\
(n=13)\end{array}$} & \multirow[b]{2}{*}{$\begin{array}{l}\text { Deceased after } \\
1986(n=20)\end{array}$} & \multicolumn{3}{|c|}{ Difference ( $p$ value) } \\
\hline & & & & & $\begin{array}{l}\text { Remission vs } \\
\text { non-remission }\end{array}$ & $\begin{array}{l}\text { Participants vs } \\
\text { non-participants }\end{array}$ & $\begin{array}{l}\text { Deceased vs } \\
\text { all others }\end{array}$ \\
\hline \multicolumn{8}{|l|}{ Smoking habits } \\
\hline Non-smokers & $7(43.8)$ & $100(39.8)$ & $3(23.1)$ & $6(31.6)$ & & & \\
\hline Ex-smokers & $2(12.5)$ & $86(34.3)$ & $2(15.4)$ & $8(42.1)$ & 0.135 & 0.026 & 0.656 \\
\hline Smokers & $7(43.8)$ & $65(25.9)$ & $8(61.5)$ & $5(26.3)$ & & & \\
\hline \multicolumn{8}{|l|}{ Lung function } \\
\hline $\mathrm{FEV}_{1} \%$ pred median (range) & $85(57-113)$ & $85(35-134)$ & $86(69-123)$ & $69(12-116)$ & 0.873 & 0.210 & $<0.001$ \\
\hline $\mathrm{FEV}_{1} \%<80 \%$ predicted & $5(31.3)$ & $90(35.9)$ & $4(33.3)$ & $15(75.0)$ & 1.000 & 1.000 & 0.001 \\
\hline \multicolumn{8}{|l|}{ Symptoms and medicines } \\
\hline Chronic productive cough & $4(25.0)$ & $104(41.4)$ & $8(61.5)$ & $15(75.0)$ & 0.082 & 0.193 & 0.018 \\
\hline Persistent wheeze & $2(12.5)$ & $72(28.7)$ & $3(23.1)$ & $10(50.0)$ & 0.250 & 1.000 & 0.045 \\
\hline Asthma medicines daily & $1(6.3)$ & $74(29.5)$ & $2(15.4)$ & $9(45.0)$ & 0.047 & 0.525 & 0.123 \\
\hline \multicolumn{8}{|l|}{ Age at onset of asthma ${ }^{\star}$} \\
\hline $0-19$ years & $6(37.5)$ & $58(23.1)$ & & & & & \\
\hline $20-39$ years & $5(31.2)$ & $84(33.5)$ & \}$^{\star}$ & \}$^{\star}$ & 0.473 & \}$^{\star}$ & \}$^{\star}$ \\
\hline$\geqslant 40$ years & $3(18.8)$ & $69(27.5)$ & & & & & \\
\hline Don't know & $2(12.5)$ & $40(15.9)$ & & & & & \\
\hline
\end{tabular}

${ }^{\star}$ Data about age at onset of disease were not avaible for non-participants or deceased. 
failed to reach statistical significance. If the 58 subjects with suspected asthma, of which 13 were in remission in 1996, were also included in the logistic model, cessation of smoking became a significant independent factor for remission (OR 6, 95\% CI 1.4 to 19 ).

INTERVIEW DATA

Fifteen of the 16 subjects who had a clinical diagnosis of asthma in 1986 and were in remission in 1996 were examined in more detail using a structured interview. None of the 15 reported recurrent wheeze or attacks of shortness of breath. Five subjects were completely free from respiratory symptoms and had not used asthma medicines at all during the previous 12 months.

\section{Discussion}

The validity of the results is dependent on the participation rate and the representativeness of the asthmatic subjects under study and, furthermore, on the definitions of asthma and of remission of asthma.

The asthma cohort was derived from a population study and the subjects had been clinically examined. ${ }^{8}$ However, the criteria for asthma were distinct and, according to modern day practice, milder symptomatics might have been classified as having asthma. We have therefore also considered the outcome of the 60 subjects with suspected asthma. In some subjects it was not possible to distinguish between asthma and COPD, and these subjects were not included in the asthma cohort.

The subjects who had died during the 10 year period had more severe disease, and the non-participants had more symptoms and were more often smokers, all factors not predicting remission. The fact that we have succeeded in keeping a large proportion of the cohort within the study supports the validity of the results.

There is no generally accepted definition of remission. In the few studies of remission of asthma in adults it has been defined differently. ${ }^{16}$ We have defined remission as the absence of use of asthma medicines and of recurrent wheeze and attacks of shortness of breath, as asthma is defined as a symptomatic condition. ${ }^{10}$

The remission of asthma was low in this middle aged and elderly cohort of asthma subjects, $6 \%$ in the 10 year period. Among the 58 symptomatic subjects classified as suspected of having asthma, the remission rate was $22 \%$. If they had been included as asthmatics in this study, the annual remission rate would have been less than $1 \%$.

In the Tucson report the criteria for remission was similar to ours but the rate of remission was somewhat greater. Thirty out of 136 asthmatics had gone into remission during a nine year period. ${ }^{1}$ A Dutch study defined remission in two ways ${ }^{6}$ - absence of bronchial hyperresponsiveness or the absence of asthma symptoms with a normal $\mathrm{FEV}_{1}$ and no hyperresponsiveness, which resulted in an extremely low remission rate.

The limited number of asthma patients in remission in our study lacked sufficient power to reach significance when performing risk factor analyses. However, stopping smoking became a significant factor when the subjects with suspected asthma in 1986 were included in the model. Cessation of smoking has not previously been shown to predict remission of asthma, ${ }^{611}$ although smoking is related to a deterioration of asthma. ${ }^{12}$

Others have also shown mild disease to be a factor associated with remission. ${ }^{16}$ The degree of bronchial obstruction and hyperresponsiveness in childhood has been shown to be associated with the outcome of childhood asthma. ${ }^{11}$

Self-administered questionnaire based data may give greater remission rates than interview or clinically based data. Some asthmatic subjects regard themselves as healthy due to improvement and deny symptoms when filling questionnaires but remember subtle symptoms in an interview situation. In one study asymptomatic former asthmatic subjects were still hyperreactive. ${ }^{13}$

We conclude that remission of asthma or change of asthma to a non-symptomatic latent phase is rare in middle aged and elderly subjects. We thank the Swedish Heart-Lung Foundation and the Swedish
Council for Working Life for financial support. The research assistants Ann-Christine Jonsson and Mai Lindström are acknowledged for epidemiological field work in collecting data.

1 Bronniman S, Burrows B. A prospective study of the natural history of asthma. Remission and relapse rate. Chest 1986;90:480-4.

2 Almind $M$, Viskum $K$, Evald T, et al. A seven year follow up of 343 adults with bronchial asthma. Dan Med Bull of 343 adults

3 Kelly WJ, Hudson I, Phelan PD, et al. Childhood asthma in adult life; a further study at 28 years of age. $B M \mathcal{F}$ 1987;294:1059-62.

4 Strachan DP, Butland B, Anderson RH. Incidence and prognosis of asthma and wheezing illness from early childhood to age 33 in a national British cohort. BMF 1996;312: 1195-9.

5 Jonsson JA, Boe J, Berlin E. The long-term prognosis of childhood asthma in a predominantly rural Swedish county. Acta Paediatr Scand 1987;76:950-4.

6 Panhuysen CIM, Vonk JM, Koeter GH, et al. Adult patients may outgrow their asthma. A 25-year follow-up study. Am may outgrow their asthma. A 25-year follow-

7 Lundbäck B, Nyström L, Rosenhall L, et al. Obstructive lung disease in Northern Sweden: respiratory symptoms assessed in a postal survey. Eur Respir f 1991;4:257-66.

8 Lundbäck B. Asthma, chronic bronchitis and respiratory symptoms, prevalence and important determinants. The Obstructive Lung Disease in Northern Sweden study I. Umeå Univ Med Dis 1993.

9 Rönmark E, Lundbäck B, Jönsson E, et al. Incidence of asthma in adults - report from the Obstructive Lung Disease in Northern Sweden study. Allergy 1997;52:1071-8.

10 American Thoracic Society. Standards for the diagnosis and care of patients with chronic obstructive pulmonary disease (COPD) and asthma. Am Rev Respir Dis 1987;136:225-44.

11 Gerritsen J, Koeter GH, Postma DS, et al. Prognosis of asthma from childhood to adulthood. Am Rev Respir Dis 1989;140:1325-30.

12 Martin AJ, Landau LI, Phelan PD. Asthma from childhood at age 21 ; the patient and his disease. BMF 1982;284:3802 .

13 Boulet LP, Turcotte H, Brochu A. Persistence of airway obstruction and hyper-responsiveness in subjects with asthma remission. Chest 1994;105:1024-31. 